\section{Surfactant Directed Chemical Vapour Deposition of Gold Nanoparticles with Narrow Size Distributions}

\section{Robert G. Palgrave and Ivan P Parkin*}

\author{
* Department of Chemistry, University College London, \\ 20 Gordon Street, London, WC1H OAJ, \\ United Kingdom \\ E-mail: rpalgrave@yahoo.co.uk
}

Gold nanoparticle arrays are currently of great interest due to their unique and tunable optical and electrical properties. (1-5) Several applications of these materials have been suggested, such as substrates for surface enhanced Raman spectroscopy, non-linear optical devices and optical gratings. The materials properties of these arrays are determined by the size, shape and separation of the nanoparticles; control of these attributes is therefore critical to the successful design of functional materials. Synthetic methods use to create nanoparticle arrays have been recently reviewed in great detail; (4) the principle methods are Langmuir-Blodgett assembly and electrophoretic deposition. $(4,6)$ Chemical vapour deposition is an industrially used technique for depositing thin films on a variety of substrates. (7-9) We have previously reported the deposition of gold nanostructured films using aerosol assisted CVD (AACVD) from preformed gold nanoparticle precursors. (10) In this communication we report the use of hydrogen tetrachloroaurate $\left(\mathrm{HAuCl}_{4} \cdot 3 \mathrm{H}_{2} \mathrm{O}\right)$ and tetraoctylammonium bromide (TOAB) as AACVD precursors to form films of metallic gold nanoparticles with narrow size distributions. It is thought that TOAB acts to direct the growth of the particles during the deposition process in an analogous fashion to the widely known solution phase synthesis of spherical gold particles. (11) In contrast, we have recently reported that films deposited in a similar manner from $\mathrm{HAuCl}_{4}$ alone resulted in particles with very wide size and shape distributions. (12)

Aerosol Assisted CVD was carried out using a horizontal bed cold wall CVD reactor previously described in detail. (10) Templated gold films were deposited using a solution of hydrogen tetrachloroaurate trihydrate $\left(\mathrm{HAuCl}_{4} \cdot 3 \mathrm{H}_{2} \mathrm{O}\right)$ and tetraoctylammonium bromide (TOAB) of various concentrations in methanol $(40 \mathrm{~mL})$. Upon addition of TOAB to the solution of $\mathrm{HAuCl}_{4}$, the solution changed in colour from pale yellow to dark orange over a period of 5-10 minutes. An aerosol generated from this solution using an $20 \mathrm{kHz}$ ultrasonic device. The mist thus produced was transported to the reactor by a flow of nitrogen at a flow rate of $2.0 \mathrm{~L} \mathrm{~min}^{-1}$. The precursor mist passed through a mixing chamber before entering the reactor between the heated substrate and an unheated top plate placed parallel to the substrate and $8 \mathrm{~mm}$ above it. Depositions were carried out at substrate temperatures between $400^{\circ} \mathrm{C}$ and $600^{\circ} \mathrm{C}$. The films were deposited onto the $\mathrm{SiO}_{2}$ barrier layer of chemically cleaned float glass supplied by Pilkington Class Plc.

In all cases deposition occurred on the substrate and top plate. Only analysis of the substrate shall be considered here. The film characteristics varied along the length of the substrate with distance from the precursor inlet. Moving along the substrate from the aerosol inlet, the substrates appeared colourless, red, blue, red, then colourless in transmitted light. In reflected light, the films appeared metallic gold. Scanning electron micrographs were taken along the length of a film deposited at $500^{\circ} \mathrm{C}$ from a solution of $\mathrm{HAuCl}_{4} \cdot 3 \mathrm{H}_{2} \mathrm{O}(0.080 \mathrm{~g})$ and TOAB $(0.50 \mathrm{~g})$ in methanol (50 $\mathrm{mL}$ ). Figure 1 shows scanning electron micrographs (A, B, C, 


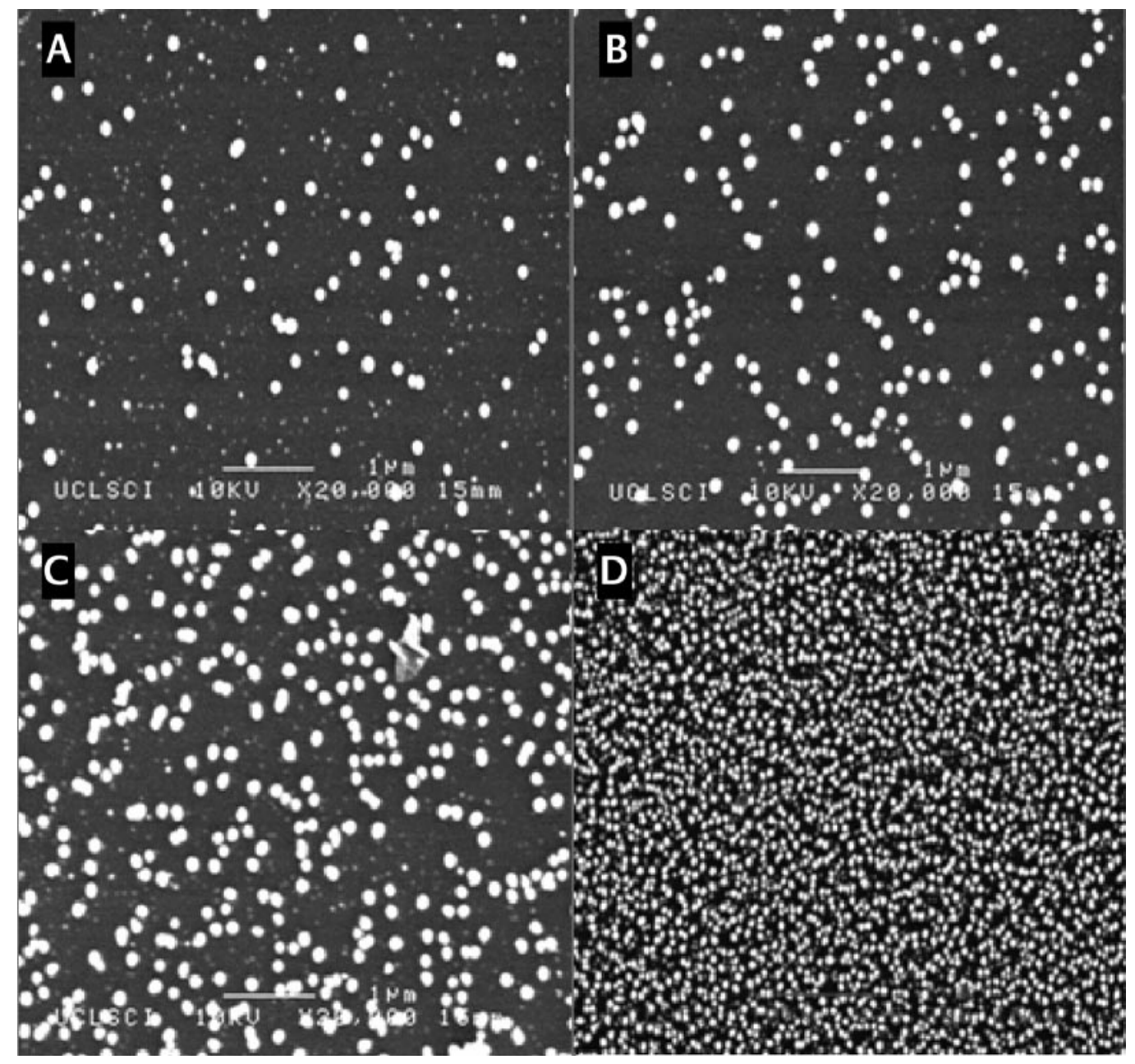

\section{Figure 1}

Scanning electron micrographs of a gold nanoparticle film deposited from $\mathrm{HAuCl}_{4}$ and TOAB. A, $4.3 \mathrm{~mm} \mathrm{B,} 6.3 \mathrm{~mm} \mathrm{C,} \mathrm{9.6} \mathrm{mm} \mathrm{D,} 14.1 \mathrm{~mm}$ along the length of the substrate

D) taken at 4.3, 6.3, 9.6, $14.1 \mathrm{~mm}$ along the length of the substrate respectively. Spherical gold particles are clearly discernable, the coverage increasing with increasing distance along the substrate. In image $D$, it is evident that coverage is in excess of one monolayer, but despite this, the nanoparticulate structure of the film remains. Particle size distributions were calculated from images A, B and C, as in these images the particle edges were clearly discernable. It is often found that the size distribution of finely divided particles is lognormal. (13-16) In some reports, however, gold nanoparticles have been produced with normal size distributions. (17) A probability plot was used in order to determine which distribution best fits the particles produced in this report. Figure 2 shows the histogram of particle sizes taken from image $C$ and, inset, a probability plot of the cumulative frequency against the diameter, $d$, and log diameter, $\log (d)$. The histogram is nearly symmetric, suggesting a normal distribution; this is confirmed by the straight line seen in the probability plot against $d$. In contrast, the probability plot against log $\mathrm{d}$ shows greater deviation from linearity, showing that a lognormal distribution is not appropriate. (17) Size distributions taken from images A, B, C were therefore fitted with normal distributions with mean particle diameter, <d>, 117, 120, $121 \mathrm{~nm}$ and standard deviation, $\sigma, 14,13,18 \mathrm{~nm}$ respectively. The sample sizes were 138, 192 and 230 particles respectively. The values of $<d>$ and $\sigma$ showed little variation over the length of the substrate. The percentage standard deviations of $12,11,18 \%$ respectively compare favourably with those observed in optimised solution phase gold nanoparticle syntheses.(1821) Particle geometry was assessed by measuring the aspect ratio (ratio of long axis to short axis). $80 \%$ of particles in image $B$ (figure 1) had aspect ratio below 1.3 , and no particles were observed with aspect ratio greater than 1.6. The particles produced in this method are therefore highly spherical; no rods, cubes or other geometries were observed in any portion of the film.

The mean size of the particles could be changed by changing the deposition conditions. Increasing the amount of TOAB used to $1.0 \mathrm{~g}$ led to particles with mean size $95 \mathrm{~nm}$ and standard deviation $13 \mathrm{~nm}$. Decreasing the deposition temperature to $400^{\circ} \mathrm{C}$ led to particles with mean diameter 

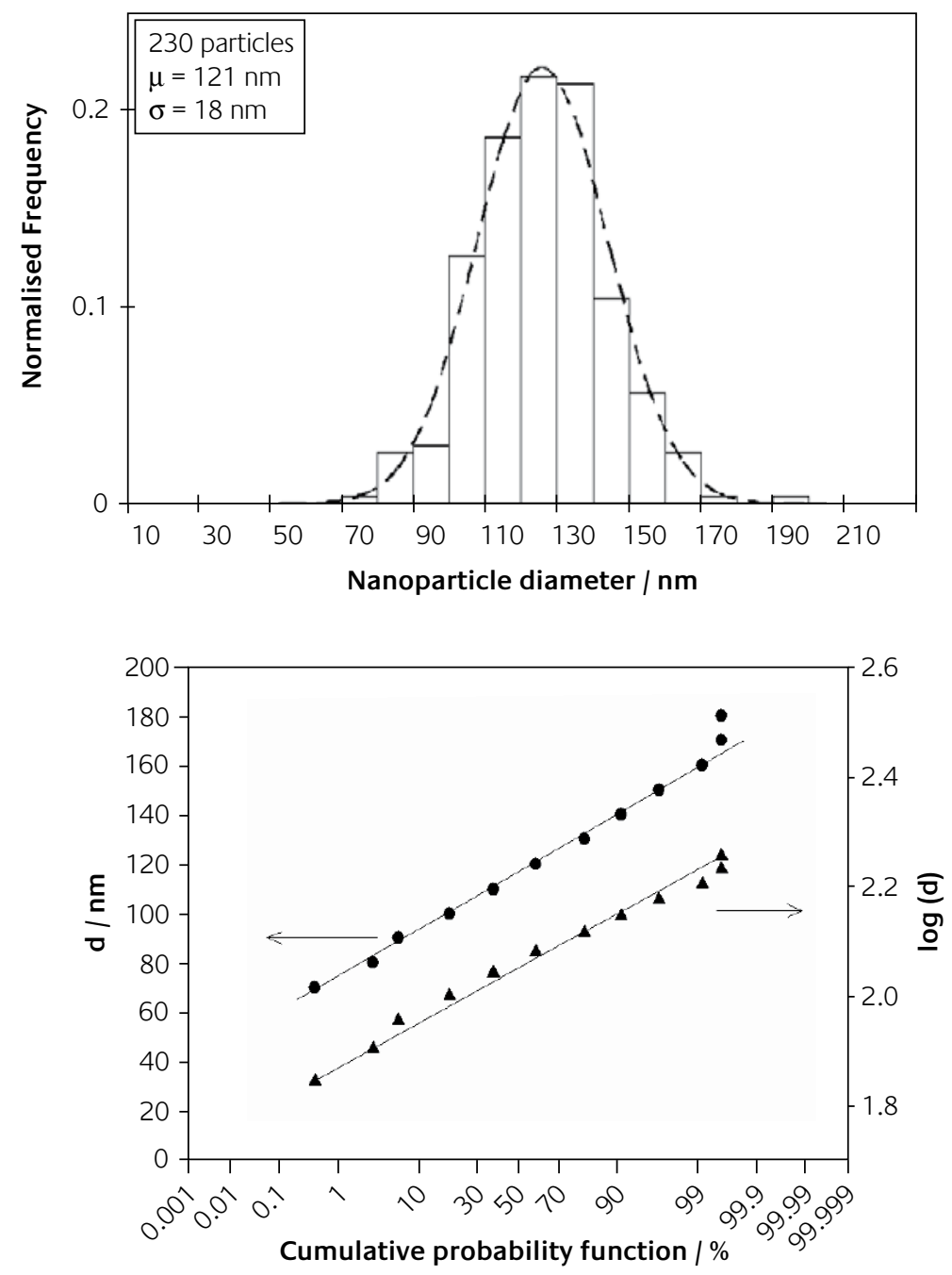

Figure 2

Above: Size distribution of particles from image C, figure 1. The dotted line is a normal fit with the parameters specified inset. Below: Probability plot of the same data; the more linear fit was found to the normal over the log-normal distribution

$101 \mathrm{~nm}$ and standard deviation $40 \mathrm{~nm}$. The effects of changing deposition parameters must be investigated more extensively and in more detail, but these initial results suggest that the particle size distribution might be easily tuned by changing experimental parameters.

The optical properties of the nanoparticle films were investigated using UV / vis spectroscopy. In all films a plasmon resonance band was observed, showing that the films are nanoparticulate in nature and not continuous gold films. $(22,23)$ The wavelength of the plasmon band absorption maximum varied along the length of the substrate, ranging from $575 \mathrm{~nm}$ to $693 \mathrm{~nm}$. The optical properties of films of gold nanoparticles have been studied in detail by several groups. (24-27) At low volume fraction of gold, particles behave independently, and show plasmon absorption similar to that of isolated nanoparticles. At higher volume fractions, the plasmon absorption is red shifted due to inter-particle coupling. A plasmon absorption around $575 \mathrm{~nm}$ corresponds to low volume fraction ( $\sim$ 0.2) gold films in which the particles show little interaction with each other. A plasmon peak around $693 \mathrm{~nm}$ corresponds to a dense film with gold volume fraction around 0.6. (27) It should be reiterated that the particle size remains almost constant throughout the film, only the separation changes. The plasmon properties of the film can therefore be tuned within a reasonably large portion of the visible spectrum.

Glancing angle X-ray diffraction (XRD) confirmed the presence of crystalline cubic gold in all films. Cubic Au [111] and [200] peaks were recorded at $2 \theta$ values of $38.4^{\circ}$ and $44.2^{\circ}$ respectively $\left(\lambda=1.540 \times 10^{-10} \mathrm{~m}\right)$. These peak positions and the FWHM were invariant along the length of the substrate in each film, showing a constant crystallite size.

In conclusion, nanoparticulate films with narrow size distributions have been deposited from simple inorganic precursors using a one step AACVD process. The films showed invariant particle diameter over the length of the substrate, and showed optical properties characteristic of films of gold particles of different volume fractions. Furthermore, the particle sizes could be changed by altering the deposition temperature and precursor concentrations. 


\section{About the Authors}

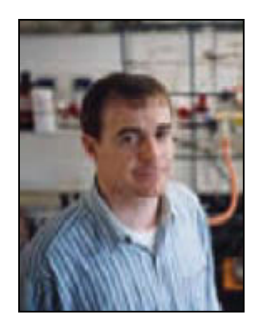

Ivan Parkin is Professor of Inorganic and Materials Chemistry at University College London and Wolfson-Royal Society Merit Award holder. He obtained his first degree and $\mathrm{PhD}$ at Imperial College and was a postdoctoral fellow at the University of Indiana. He was promoted to Professor at UCL in 2000. His laboratory focuses on the preparation of inorganic and nanostructured materials by innovative routes. His group have developed new hydrophilic coatings on glass and new solid state gas sensors by CVD.

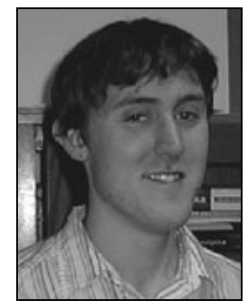

Robert Palgrave is a PhD student in Professor Parkin's laboratory. He also holds a University demonstratorship position in the Chemistry Department. Robert obtained a first class honours degree from UCL in 2003. His research interests focus on the preparation of self cleaning films, nanostructured gold films and the incorporation of nanoparticles within a host matrix.

\section{Acknowledgement}

This work was supported financially by the Department of Chemistry, University College London.

\section{References}

1 M. Brust, D. Bethell, C. J. Kiely and D. J. Schiffrin, Langmuir 14, (19), 54255429 (1998)

2 M. Brust, D. Bethell, D. J. Schiffrin, and C. J. Kiely, Advanced Materials 7, (9), 795-\& (1995)

3 M. D. Musick, C. D. Keating, L. A. Lyon, S. L. Botsko, D. J. Pena, W. D. Holliway, T. M. McEvoy, J. N. Richardson and M. J. Natan, Chemistry Of Materials 12, (10), 2869-2881 (2000)

4 J. H. Fendler and F. C. Meldrum, Advanced Materials 7, (7), 607-632 (1995)
5 C. W. Corti, R. J. Holliday and D. T. Thompson, Gold Bulletin 35, (4), 111-136 (2002)

6 T. Teranishi, M. Hosoe and M. Miyake, Advanced Materials 9, (1), 65-\& (1997)

7 X. H. Hou and K. L. Choy, Chemical Vapor Deposition 12, (10), 583-596 (2006)

8 R. Gordon, Journal Of Non-Crystalline Solids 218, $81-91$ (1997)

9 R. J. McCurdy, Thin Solid Films 351, (1-2), 66-72 (1999)

10 R. G. Palgrave and I. P. Parkin, Journal Of The American Chemical Society 128, (5), 1587-1597 (2006)

11 M. Brust, M. Walker, D. Bethell, D. J. Schiffrin and R. Whyman, Journal Of The Chemical Society-Chemical Communications, (7), 801-802 (1994)

12 R. G. Palgrave and I. P. Parkin, Chem. Mater. 19, (19), 4639-4647 (2007)

13 V. Privman, D. V. Goia, J. Park and E. Matijevic, Journal Of Colloid And Interface Science 213, (1), 36-45 (1999).

14 M. J. Hostetler, J. E. Wingate, C. J. Zhong, J. E. Harris, R. W. Vachet, M. R. Clark, J. D. Londono, S. J. Green, J. J. Stokes, G. D. Wignall, G. L. Glish, M. D. Porter, N. D. Evans and R. W. Murray, Langmuir 14, (1), 17-30 (1998)

15 L. B. Kiss, J. Soderlund, G. A. Niklasson, and C. G. Granqvist, Nanostructured Materials 12, (1-4), 327-332 (1999)

16 K. Nakamura, T. Kawabata and Y. Mori, Powder Technology 131, (2-3), 120-128 (2003)

17 R. Seshadri, G. N. Subbanna, V. Vijayakrishnan, G. U. Kulkarni, G. Ananthakrishna and C. N. R. Rao, Journal Of Physical Chemistry 99, (15), 5639-5644 (1995)

18 J. Kimling, M. Maier, B. Okenve, V. Kotaidis, H. Ballot and A. Plech, Journal Of Physical Chemistry B 110, (32), 15700-15707 (2006)

19 S. H. Chen and K. Kimura, Langmuir 15, (4), 1075-1082 (1999)

20 N. R. Jana, L. Gearheart and C. J. Murphy, Chemistry Of Materials 13, (7), 2313-2322 (2001)

21 J. Rodriguez-Fernandez, J. Perez-Juste, F. J. G. de Abajo and L. M. Liz-Marzan, Langmuir 22, (16), 7007-7010 (2006)

22 A. I. Maaroof, M. B. Cortie and G. B. Smith, Journal Of Optics A-Pure And Applied Optics 7, (7), 303-309 (2005)

23 S. Yamaguchi, Journal Of The Physical Society Of Japan 15, (9), 1577-1585 (1960)

24 L. M. Liz-Marzan, Langmuir 22, (1), 32-41 (2006)

25 P. Mulvaney, Langmuir 12, (3), 788-800 (1996)

26 T. Ung, L. M. Liz-Marzan and P. Mulvaney, Journal Of Physical Chemistry B 105, (17), 3441-3452 (2001)

27 T. Ung, L. M. Liz-Marzan and P. Mulvaney, Colloids And Surfaces A-Physicochemical And Engineering Aspects 202, (2-3), 119-126 (2002) 